\title{
Derecho Eclesiástico Peruano
}

\section{Disposiciones estatales sobre la Iglesia}

\author{
Por el Presbítero Doctor JOSE DAMMERT BELLIDO \\ Catedrático de la Pontificia Universidad Católica.
}

Las relaciones ente la Iglesia y el Estado fundamentalmente se rigen por la Bula "Praeclara inter beneficia" del Papa Pío IX, que concedió en 1874 el derecho de Patronato al Jefe del Estado del Perú, bula promulgada en 1880 por Decreto del Dictador Don Nicolós de Piérola.

Para determinar dichas relaciones, el Estado Peruano ha incluído en su Constitución, Códigos y Leyes, disposiciones que reglamentan algunos puntos y que brevemente comentaré en las líneas siguientes.

Los textos legislativos a que hago referencia son los siguientes:

Constitución Política de la República Peruana (1933).

Código Civil (1936).

Código de Procedimientos Civiles (1912).

Código Penal (1924).

Código de Procedimientos Penales (1939).

Ley NP 9166 (Reforma Constitucional de 1940).

La Constitución Política dedica un título especial (XIV) a la Religión. Representa una innovación respecto $\alpha$ las constituciones anteriores, porque en estas uno de los primeros artículos era dedicado siempre a expresar la profesión religiosa del Estado y las otras disposiciones estaban diseminadas entre las atribuciones de los poderes legislativo y ejecutivo.

\section{REIIGION.}

"Respetando los sentimientos de la mayoría nacional, el Estado protege la religión católica apostólica y romana. Las demás religiones gozan de libertad para el ejercicio de sus respectivos cultos". (Art. 232 Constitución de 1933).

Este artículo modifica la tradición constitucional de la República que constantemente declaraba que "El Estado profesaba la religión católica". En la disposición de 1933 el Estado no profesa ninguna religión, sino que ateniéndose al hecho de que la mayoría de la población es católica, protege a esta religión. 
Acerca de este artículo es interesante la intervención del Doctor V. $\AA$. Belaúnde en el Congreso Constituyente, publicada en el "Debate constitucional" con el rabro "Iglesia y Estado".

\section{PATRONATO.}

Sin referirse a la Bula de Patronato el Art. 233 de la Constitución declara "El Estado ejerce el Patronato Nacional conforme a las leyes y a las prócticas vigentes".

El Art. 154 inc. 21), incluye entre las atribuciones del Presidente de la República "Ejercer el Patronato Nacional con arreglo a las leyes y prácticas vigentes".

Según la mente del legislador, el Presidente de la República para el ejercicio del patronato personifica al Estado, lo que es conforme a la Bula de Patronato.

En estas disposiciones constitucionales se reproduce una frase derivante de la tradición colonial y republicana, pues es antigua y sabe $\alpha$ regalismo: lo de "a las leyes y prácticas vigentes". Disposición imprecisa que deja al arbitrio de los funcionarios de la Dirección de Culto la averiguación de cuáles son las prócticơs vigentes.

\section{CONCORDATO.}

La Constitución (Art. 234) renueva el antiguo precepto de celebrar concordato con la Santa Sede. En el artículo original se prescribía "las relaciones entre el Estado y la Iglesia Católica, se regirán por un concordato celebrado con arreglo a las instrucciones dadas por el Congreso". La reforma constitucional de 1940 modificó ese artículo por el siguiente: "Las relaciones entre el Estado y la Iglesia Católica se regirán por Concordatos celebrados por el Poder Ejecutivo y aprobados por el Congreso" (Ley No 9166 Art. 3\%; el Art. 4 suprime el inc. 22), Art. 154 de la Constitución).

La reforma constitucional alivió el trámite para la celebración del Con. cordato, suprimiendo las instrucciones previas del Congreso que nunca se llegaron a dar y dejando la iniciativa al Poder Ejecutivo. A pesar de ello no han culminado las gestiones para llevar a cabo la celebración de un concordato.

\section{ARZOBISPOS Y OBISPOS.}

a) Con un fuerte sentido nacionalista se prescribe que, "para desempeñar los cargos de Arzobispo y Obispo, se requiere ser peruano de nacimiento" (Art. 235 Constitución). En líneas generales este precepto coincide con la política de la Sede apostólica de farorecer el surgimiento del clero indígena en todas partes. Sin embargo, parece que su lugar debe estar en el concordato y no en la Constitución Política;

b) En plena conformidad con la Bula de Patronato el Art. $2^{\circ}$ de la ley 9166 determina: "Los eclesiásticos peruanos de nacimiento, que de 
ban ocupar las vacantes de los Arzobispados y Obispados serán designados por el Presidente de la República, en Consejo de Ministros. El Jefe del Estado hará la presentación ante la Santa Sede y dará el pase a las bulas respectivas". Explícitamente se derogaron los incisos 14) del Art. 123 y 23) y 24) del Art. 154 de la Constitución, por los cuales el Congreso se había reservado la designación de arzobispo y obispos con violación de la Bula de Patronato que concede la facultad de presentación exclusivamente al Jefe del Es. tado Peruano.

La sabiduría de esta reforma constitucional ha encontrado su más amplio apoyo en la rapidez con que se han llenado las vacan. tes producidas desde su promulgación.

c) Dada la dignidad episcopal, los Códigos de Procedimientos asimilan a los abispos al Presidente de la República para los efectos de prestar testimonio: "El Presidente de la República, el Arzobispa y los Obispos, en sus respectivas Diócesis, declararán, a su elección, en su domicilio o en local de su despacho" (Art. $148 \mathrm{del} \mathrm{C.}$ de P.P. Art. 484 del C. de P. C.

\section{CIRCUNSCRIPCIONES ECLESIASTICAS}

Es atribución del Congreso "Crear nuevos Arzobispados y Obispados, - suprimir los ya existentes a solicitud del Poder Ejecutivo" (Art. $1^{\circ}$ Ley No 9166). Se sobrentiende que estas disposiciones están sujetas a la aprobación de la Santa Sede.

En uso de estas facultades se elevaron a la categoría arzobispal las diócesis de Cuzco, Arequipa y Trujillo en 1943, y se crearon los Obispados de Huancayo, Huancavelica y Tacna en 1945, y de Ica en 1946.

\section{PASE A LOS DECRETOS PONTIFICIOS}

Una disposición de cuño totalmente regalista y anacrónica, atribuye al Presidente de la República la facultad de "conceder o negar el pase, con asentimiento del Congreso, y oyendo previamente a la Corte Suprema de Justicia, si se relacionoren con asuntos contenciosos, a los Decretos Conciliarios, Breves y Rescriptos Pontificios, y a las Bulors, cuando no se refieran a la institución de Arzobispo u Obispo" (Art. 154 inc. 26, de la Constitución).

El Código Penal sanciona como culpable de rebelión al funcionario público o eclesiástico que intrinja esta disposición: (Art. 304) "El funcionario público o ministro eclesiástico que ejecutare oficialmente en la República, bula, breve o rescripto pontificio, o les diere curso, sin cumplir los requisitos que las leyes prescriben, será reprimido con inhabilitación conforme a los incisos $1^{\circ}$ ) y $3^{\circ}$ ) del Ârt. 27, por tiempo no mayor de un año y multa de la renta de tres a noventa días. ( $1^{\circ}$ pérdida del mandato, cargo, empleo o comisión que ejercía el penado, aunque provenga de elección popular: $3^{\circ}$ Incapacidad para obtener mandatos, cargos, empleos y comisiones públicas"). 


\section{PRESENTACION A CARGOS ECLESLASTICOS}

La Bula de Patronato confiere al Presidente de la República ademós del derecho de presentar candidatos para las vacantes episcopales, la facultad enumerada en el inc. 25) del Ârt. 154 de la Constitución, que dice: "Hacer presentaciones para las dignidades y canongías de las Catedrales, y para los curatos y demás beneficios eclesiásticos, con arreglo a las leyes y prácticas vigentes". Por supuesto, como se ha señalado anteriormente, la última frase no se encuentra en la Bula.

\section{LIMITACIONES A LOS ECLESIASTICOS}

A.-Al Clero en general.

a) Diferentes disposiciones constitucionqles prescriben "que no son elegibles diputados ni senadores los miembros del Clero" (Art. 100); "que son inelegibles Presidente y Vice-Presidentes de la República.... los miembros del Clero (Art. 137, inc. 5; y ley 8237 de $1^{\circ}$ de abril de 1936); no pueden ser nombrados Ministros de Estado.... los miembros del Clero" (Art. 161).

Estos preceptos quitan a los miembros del Clero el derecho de integrar los poderes legislativo y ejecutivo, en contra de la tradición constitucional que lo permitía y por la cual el Primer Congreso Constituyente fué presidido por el clérigo Francisco Javier de Luna Pizarro e integrado por 25 eclesiásticos más y en todos los otros Congresos siempre intervinieron sacerdotes hasta el gobierno del Presidente Leguía inclusive, entre ellos Bartolomé Herrera $y$ Monseñor Tovar que también fueron Ministros de Estado.

Creo, sin embargo, que se trata de una norma sagaz, que hubiera sido preferible se incorporará al Concordato previsto, como renuncia que hace la Iglesia $Y$ no como mera disposición unilateral del Estado;

b) Totalmente justificada es la inhabilitación ordenada por el Código Civil en materia de testamentos: "No producen efectos las disposiciones del testador, hechas durante su última enfermedad, en favor de su confesor o ministro de culto o del médico, que lo hayan asistido en esa enfermedad" (Art. 668). La finalidad está en evitar toda sospecha de coacción sobre la última voluntad del enfermo.

\section{B. - A los religiosos.}

a) "El ejercicio de la ciudadanía se suspende: por profesión religiosa" (Art. 85, inc. 2) de la Constitución).

b) "No pueden ser apoderados: el ciego, el sordo-mudo y el fraile, a no ser de su convento" (Art. $7^{\circ}$ del Código de Procedimientos Civiles). 
Estas dos disposiciones no tienen razón de ser, y menos aún en la for$m a$ vejatoria en que aparecen, pues se enumera $\alpha$ los religiosos entre los incapaces físicos y mentales y los condenados a pena privativa de la libertad. El voto de obediencia prestado por los religiosos no los incapacite al ejercicio de la ciudadanía o del mandato, pues en situación similar estarían los miembros de los partidos políticos que votan por los candidatos escogidos por sus Juntas Directivas.

\section{ASOCLACIONES RELIGIOSAS}

Las asociaciones religiosas gozan de personería jurídica de acuerdo a lo dispuesto en el Art. 44 del Código Civil: "Las asociaciones cuyo objeto no es realizar un fin económico gozarán de personería jurídica si tienen peculio propio o proveen en sus estatutos la manera de formarlo y si sus estatutos conston de escritura pública inscrita".

\section{MATRIMONIO.}

\section{A.-Deberes religiosos.}

"Las disposiciones de la ley, en lo concerniente al matrimonio no se extienden más allá de sus efectos civiles, dejando íntegros los deberes que la religión impone" (Cód. Civil Art. 292).

Se reconoce el pleno derecho de la Iglesia a legislar en lo que se refiere al matrimonio canónico, y se determina la no intromisión del Estado en este campo.

\section{B. - Mutrimonio civil efectuado por un sacerdote.}

El Código Civil autoriza en algunos casos a los sacerdotes católicos a celebrar el matrimonio civil, prescribiendo que "no producirá efectos civiles el matrimonio celebrado conforme a los Arts. 120 y 124 mientras no se inscriba en el registro civil" (Art. 126).

a) Por delegación escrita.

"El alcalde podrá delegar por escrito en..., capellanes de hospitales y misioneros católicos la facultad de celebrar matrimonio", (Art. 115).

b) En peligro de muerte.

"Si alguno de los contrayentes estuviere en inminente peligro de muerte, el matrimonio podrá celebrarse sin observar las forma. lidades que deben precederle. Este matrimonio se celebrará ante el párroco o cualquier otro sacerdote y no producirá efectos civiles cuando se contraiga entre personas incapaces". (Art. 120).

c) Ante el párroco o el Ordinario del lugar.

"El matrimonio civil podrá celebrarse también ante el párro. co o el Ordinario del lugar, o ante el sacerdote a quien alguno de los dos delegue esta Facultad". 


\begin{abstract}
"Al acto asistirá el funcionario del registro civil, para verificar la inmediata inscripción del matrimonio".

"Si no existiere dicho funcionario, el párroco o el Ordinario remitirá inmediatamente un certificado del matrimonio a la oficina del registro civil más próxima. (Ärt. 124).

"La capacidad para contraer matrimonio puede comprobarse también, en el caso del artículo anterior, ante el párroco competente, conforme $\alpha$ éste". (Código Art. 125).
\end{abstract}

\title{
C.-Penas $\alpha$ los infraciores de las leyes civiles sobre el matrimonio.
}

"El oficial público o eclesiástico que a sabiendas autorizare un matrimonio de los comprendidos en los artículos anteriores (matrimonio de casado o con persona casada), sufrirá, en su caso, la pena que en ellos se determin $\alpha$.

Si lo autorizare sin saberlo, cuando su ignorancia provenga de no haber llenado los requisitos que la ley prescribe para la celebración de un matrimonio, la pena será de multa de tres a treinta días de renta e inhabilitación, conforme $\alpha$ los incisos $1^{\circ}$ ) y $3^{\circ}$ ) del Art. 27, po rno mós de dos años.

Sufrirá multa de la renta de tres a treinta días, el oficial público o eclesiástico que fuera de los casos de este artículo, procediere a la celebración de un matrimonio, sin haber observado todas las formalidades exigidas por la ley" (Art. 216 del C.P. vigente).

La última disposición del artículo anterior constituye una intromisión en los derechos de la Iglesia, pues no puede castigarse al ministro de ella por cumplimiento de sus deberes eclesiósticos.

Respecto a los dos primeros incisos debe aclararse si el primer matrimonio ha sido canónico o civil. Si lo primero el sacerdote no puede cele. brar el matrimonio; si lo segundo deben tenerse presente las circunstancias.

\section{SECRETO SACERDOTAL}

Reconociendo la delicadeza del ministerio sacerdotal, los códigos de procedimientos civiles y criminales declaran que:

"Estón obligados a testificor en juicio todos aquellos a quienes la ley no lo prohibe; pero esta obligación no rige en cuanto a los eclesiásticos, abogados, apoderados, médicos $Y$ matronas, sobre hechos de que han tenido conocimiento en el ejercicio de su ministerio o profesión". (Art. 457 C. Proc. Civ.).

"No podrán ser obligados a declarar: 10-Los eclesiásticos, abogados, médicos, notarios y obstetrices, respecto de los secretos que se les hubiere confiado en el ejercicio de su profesión". (Ärt. 141 C. Proc. Pen.). 
Además el Código Penal sanciona la violación del secreto sacerdotal: Art. 363: "El que teniendo noticia por razón de su estado, oficio, empleo, profesión o arte, de secretos cuya publicación pudiere causar daño, los revelare $\sin$ consentimiento del interesado o sin que la revelación fuere necesaria para salvaguardar un interés superior, será reprimido, por acción del perjudicado, con prisión no mayor de dos años o multa de la renta de tres a noventa días e inhóbilitación, conforme a los incisos $1^{\circ}$ ) y $3^{\circ}$ ) del Art. 27. por no más de tres años.

"Están especialmente comprendidos en esta disposición los eclesiásticos, abogados, apoderados, notarios, médicos, farmacéuticos, los auxiliares de estas personas y las parteras".

\section{PARTIDAS PARROQUIALES}

A.-Valor supletorio.

"Las partidas de los registros parroquiales tendrán el mismo valor que las partidas de los registros de estado civil, si se prueba, mediante la certificación respectiva, lá inexistencia de este registro en el lugar correspon. diente, sin perjuicio de lo ordenado en el Art. 126".

\section{B.-Anteriores al Código.}

"Las partidas de los registros parroquiales referentes $\alpha$ los hechos realizados antes de la vigencia de este Código, conservan la eficacia que les atribuyen las leyes anteriores.

\section{C.-Reconocimiento de hijos ilegítimos.}

"El reconocimiento de los hijos ilegítimos cuyas partidas solo estuvieran extendidas en los libros parroquiales, podrá ser efectuado en estos libros, ante el párroca, con las formalidades del Art. 355".

El Art. 1827 del Código Civil, incluído en sus disposiciones finales, era necesario en la práctica, dado que no está́ organizado el registro civil en todos los pueblos del páís, reconociendo así uno de los valiosos servicios que la Iglesia presta a la sociedad civil mediante su organización parroquial.

\section{CULTO}

A. -

Se consideran por el Código Penal delitos contra la tranquilidad pública los siguientes:

Art. 284._.'El que en público y de manera vil, escarneciera las convicciones de otro en materia de creencia o profanare los objetos de veneración religiosa, será reprimido con prisión no mayor de tres meses o multa de la renta de tres a treinta días". 
"Art. 285. - "Será reprimido con la misma pena del artículo anterior:

1--El que, por malignidad, turbare o públicamente escarneciera un acto cultual permitido por la Constitución.

2:-El que, por malignidad, profonase un lugar o un objeto destinado a un culto o acto cultual permitido por la Constitución".

Art. 287.- "El que, por malignidad, turbare o profanare un convoy fúnebre o una ceremonia religiosa, será reprimido con prisión no mayor de seis meses o multa de la renta de tres a sesenta días".

B. -

Los objetos destinados al culto son equiparados a las cosas públicas, no pudiendo ser embargados:

Juicio Ejecutivo.-Embargo.

Art. 617.- "No son embargables: 1० Las casas públicas y las desti nadas al culto" (Art. 617 del Cód. de Proc. Civiles). 